\title{
Metáforas de Lula e Alckmin nos debates de 2006 em uma perspectiva da Lingüística de Corpus ${ }^{l}$
}

\author{
Tony Berber Sardinha \\ Pontifícia Universidade Católica de São Paulo - PUC-SP
}

\begin{abstract}
RESUMO: O objetivo deste trabalho é contrastar o uso de metáforas pelos dois candidatos no segundo turno das eleições presidenciais de 2006, Luís Inácio Lula da Silva e Geraldo Alckmin, para saber até que ponto Lula, que foi vitorioso nas urnas, usou metáforas de modo mais eficaz do que o outro candidato durante os debates televisados. Foi colhido um corpus de transcrições desses debates, que foi então analisado em termos da presença de metáforas lingüísticas e conceptuais. O uso de metáforas dos dois candidatos foi contrastado e a análise revelou que houve poucas diferenças entre os candidatos. Ambos usaram quantidades parecidas delas. A principal diferença entre eles foi em relação à ênfase. Alckmin pulverizou suas metáforas: colocou em cena um número maior delas, mas com poucas ocorrências de cada. Lula foi mais seletivo e o neutralizou, conseguindo concentrar seu discurso em metáforas mais afinadas com seus propósitos. PALAVRAS-CHAVE: metáfora, Lingüística de Corpus, debates televisados
\end{abstract}

ABSTRACT: The aim of this study is to contrast the use of metaphors by the two presidential contenders in the runoff of the Brazilian presidential race of 2006, Luís Inácio Lula da Silva and Geraldo Alckmin, in order to establish if Lula, who was victorious, actually used metaphors in a more effective way than his opponent on the television debates. Metaphor use by both candidates was compared, and the analysis revealed that there were few differences between the two candidates. Both used similar quantities of them. The main difference was stress. Alckmin scattered his metaphors, by putting in place a greater number of them, with few occurrences of each. Lula, on the other hand, was more selective and neutralized his opponent, thus being able to stress metaphors that were better suited to his needs.

KEY-WORDS: metaphor, Corpus Linguistics, Brazilian presidential debates

\footnotetext{
${ }^{1}$ Agradeço o apoio das seguintes agências: CNPq, processos 350455/2003-1, 307307/2006-9, 450239/2006-3; Capes, processo 0397/04-0; FAPESP, processo 06/ 00109-9. Sou também grato pelos comentários dos pareceristas anônimos e pela leitura cuidadosa de Estela de Jesus Martins e de Cecília Lopes de uma versão anterior deste trabalho.
} 


\section{Introdução}

Os debates televisados entre candidatos a presidente da República tiveram início em 1960, entre John F. Kennedy e Richard Nixon, pela presidência dos Estados Unidos. Seu surgimento se deveu a uma confluência de fatores: a crescente importância da televisão como meio de comunicação, a presença maciça dos aparelhos de televisão nas residências e a possibilidade técnica de transmissão ao vivo de programas em rede. Além de ser o pioneiro, esse debate se tornou histórico também porque muitos o consideram um fator decisivo nessa eleição. Kennedy foi melhor e acabou eleito com apenas $0,1 \%$ de vantagem nos votos diretos. Essa vantagem pode ter sido conseguida no debate. ${ }^{2}$

No Brasil, o primeiro debate televisado entre candidatos à presidência aconteceu somente depois do fim do regime militar. Em 1988, Leonel Brizola e Franco Montoro, que eram os possíveis candidatos à eleição direta que se aproximava, foram os protagonistas do debate inaugural. ${ }^{3}$ No ano seguinte, quando se realizaram as eleições diretas para presidente, aconteceu a primeira série de debates transmitida pela TV entre os verdadeiros presidenciáveis. Luís Inácio Lula da Silva e Fernando Collor de Mello se enfrentaram no palco montado na Rede Bandeirantes em 1989, pelo segundo turno da campanha das eleições. Esse debate ficou marcado pela manipulação empreendida pela Rede Globo que, não tendo transmitido o debate, apresentou 'os melhores momentos' em horário nobre, e favoreceu Fernando Collor. ${ }^{4}$ Isso indica novamente a importância que os debates desfrutam no meio político e na mídia, à medida que a principal emissora de TV do país primeiro se recusa a transmitir o evento e depois o edita de modo a favorecer um dos candidatos. Há, portanto, toda uma aura de crucialidade que envolve os debates televisados ao vivo, motivada pela crença de que eles podem decidir uma eleição.

Há vários estudos sobre o impacto dos debates na decisão de voto dos eleitores (HELLWEG; PFAU et al., 1992; KRAUS, 2000; SCHROEDER, 2000). Abramowitz (1978) estudou as preferências de eleitores americanos

\footnotetext{
${ }^{2}$ http://www.museum.tv/debateweb/html/greatdebate

${ }^{3}$ http://www.band.com.br/grupo/jornalismo.asp. A televisão começou a transmitir os debates entre candidatos a governador em 1982.

${ }^{4}$ www1.folha.uol.com.br/folha/ especial/2002/eleicoes/historia-1990.shtml.
} 
no pleito de 1976, entre Gerald Ford e Jimmy Carter, e concluiu que os debates influenciaram os eleitores no tocante à sua conscientização política, mas não mudaram a intenção de voto. Holbrook (1999) investigou o grau de informação adquirida por eleitores em debates de TV nos Estados Unidos e concluiu que os eleitores aprendem mais sobre os candidatos menos conhecidos, principalmente nos debates iniciais. Benoit, Hansen e Verser (2003) concordam com esse achado e adicionam que os debates têm o poder de sensibilizar os eleitores a respeito dos temas debatidos, além de tornálos mais críticos em relação à avaliação que fazem dos candidatos.

Em contrapartida, os estudos da linguagem dos debates são bem mais raros, principalmente no contexto eleitoral brasileiro. A presente pesquisa visa a contribuir para o preenchimento dessa lacuna.

O objetivo deste trabalho é empreender uma análise contrastiva do discurso dos dois candidatos para verificar o uso de metáforas por Luís Inácio Lula da Silva e por Geraldo Alckmin em dois debates do segundo turno das eleições presidenciais de 2006, a fim de detectar quais metáforas foram colocadas em jogo e até que ponto essas metáforas se relacionam com o resultado das eleições, vencidas por Lula.

Há muito poucos estudos sobre as metáforas dos debates presidenciais transmitidos por TV. Cienki $(2004 ; 2005)$ pesquisou o uso das metáforas do 'Pai Rígido' ('Strict Father') e do 'Pai Provedor' ('Nurturant Parent') propostas por Lakoff (2002) nos debates da eleição americana de 2000, entre Al Gore e George W. Bush. Os resultados mostraram quase nenhuma ocorrência dessas metáforas na linguagem dos candidatos, mas várias nos gestos de Bush, que se alinhou mais diretamente com a metáfora conservadora do Pai Rígido.

A motivação inicial do presente trabalho foi a opinião generalizada de que os debates do segundo turno ${ }^{5}$ da eleição presidencial brasileira de 2006 foram marcados por dois estilos opostos. De um lado, o presidente Lula, com uma retórica afinada com a população mais simples e de outro, Geraldo Alckmin, com um discurso mais acessível à população escolarizada. Essa visão permeou as colunas políticas da imprensa. Por exemplo, segundo Piza (2006),

\footnotetext{
${ }^{5}$ Os debates do primeiro turno das eleições presidenciais foram comprometidos pela ausência do candidato Luís Inácio Lula da Silva, líder absoluto nas pesquisas de intenção de voto.
} 
Lula utiliza maior colorido de tons e semblantes: vai da auto-exaltação à ironia quase debochada, passa pelo humor e pelo confessional; ora é vítima, ora é onipotente. Trata as pessoas de modo cordial, sugerindo intimidade. (...) [Alckmin] fala por itens - como um power point, na observação de Delmo Moreira. Dá sempre a impressão de ter memorizado ponto a ponto o que os marketeiros lhe passaram e apresenta os conceitos e os números com respiração estacada, sem nuances de sentido.

Apesar dos muitos comentários na mídia, não foi dada atenção especial às metáforas, embora, segundo Charteris-Black (2005), a retórica política é marcada por metáforas condizentes com a ideologia política do orador. Ainda segundo Charteris-Black (2005), grandes líderes políticos (como Margareth Thatcher, Ronald Reagan, Bill Clinton, Tony Blair e George W. Bush) utilizam metáforas de modo sistemático para expressar suas convicções políticas, com a finalidade de persuadir os eleitores e influenciar a opinião pública.

As metáforas são uma marca registrada de Luís Inácio Lula da Silva, presidente re-eleito do país em 2006. Algumas ficaram famosas, como a da churrascaria, em que ele compara a cobrança de resultados do seu governo à pressa em saciar a fome ('encher o bucho com maionese'), e a do esporte, em que diz gostar de 'vestir a camisa' das causas que defende.

As metáforas de Lula já foram objeto de pesquisa lingüística. Segundo Berber Sardinha (em apreciação), Lula emprega diversas metáforas conceptuais para tratar do desenvolvimento, uma questão que se torna ainda mais importante no seu segundo mandato devido às promessas de campanha. E em outro estudo, Berber Sardinha (2006) investigou as metáforas conceptuais relacionadas à noção da conquista, com que o presidente lida de modo consistente e coerente com sua trajetória de vida pessoal e com suas convicções políticas, espelhando tanto a sua ascensão social (de metalúrgico a presidente da República) quanto uma ideologia marxista de luta de classes.

Por outro lado, não há pesquisas disponíveis sobre o discurso de Geraldo Alckmin, muito menos sobre as metáforas que coloca em jogo. Porém, se os comentaristas da imprensa estão corretos em suas afirmações, é possível conjeturar que a sua falta de sucesso nas urnas esteja ligada, além de outras coisas, ao uso escasso ou inadequado de metáforas.

Neste trabalho, temos como arcabouço teórico e metodológico a Teoria da Metáfora Conceptual (LAKOFF; JOHNSON, 1980) e a Lingüística de Corpus (DEIGNAN, 2005). Nas seções seguintes, apresentamos essas 
duas áreas; entretanto, devido à questão de espaço, fornecemos apenas uma visão dos conceitos efetivamente aplicados na pesquisa; para um aprofundamento em Teoria da Metáfora Conceptual e Lingüística de Corpus, recomendamos ao leitor consultar, respectivamente, Gibbs (1994) e Berber Sardinha (2004).

\section{Metáfora conceptual}

A Teoria da Metáfora Conceptual foi fundada por Lakoff e Johnson (1980) e prega que a metáfora é, acima de tudo, uma figura de pensamento. Isso contrasta com a visão tradicional da metáfora como uma figura de linguagem. Por figura de pensamento, entende-se um modelo cognitivo que guia nosso entendimento do mundo em geral. As metáforas conceptuais não são verbalizadas, mas realizam-se no discurso por meio de metáforas lingüísticas (também chamadas de expressões metafóricas). Essa realização é chamada de licenciamento, à medida em que a realização verbal está vinculada à representação mental (conceptual) da metáfora. Dessa forma, quando dizemos que uma metáfora lingüística foi licenciada, queremos dizer que se trata de uma realização verbal condizente com uma metáfora conceptual. Alguns exemplos de metáforas conceptuais comuns à cultura ocidental aparecem no QUADRO 1.

QUADRO 1

Exemplos de metáforas conceptuais e algumas de suas respectivas metáforas lingüísticas

\begin{tabular}{|l|l|}
\hline Metáfora conceptual & Metáforas lingüísticas licenciadas \\
\hline O AMOR É UMA VIAGEM & Esse namoro vai longe. \\
& O casamento chegou ao fim. \\
TEMPO É DINHEIRO & Soluções para economizar tempo. \\
& Pare de gastar tempo. \\
EMOÇÕES SÃO UM LÍQUIDO QUENTE & Estou estourando de alegria. \\
NUM RECIPIENTE. & Estou explodindo de felicidade. \\
\hline
\end{tabular}

Normalmente, as metáforas lingüísticas tendem a ser formas bastante convencionais de expressão e não são vistas como metáforas. A razão pela qual Lakoff e Johnson Lakoff e Johnson (1980) as consideram metáforas é que possuem uma metáfora conceptual subjacente que faz a ligação (ou 
mapeamento) entre dois temas ou domínios distintos. Por exemplo, no caso de o AMOR É UMA VIAGEM, ${ }^{6}$ há uma ligação entre o domínio do amor e o da viagem. Dessa ligação resulta o conceito metafórico de amor (O AMOR É UMA VIAGEM). Segundo a Teoria da Metáfora Conceptual, esse conceito metafórico reside em nossas mentes e nos faz produzir e entender as metáforas lingüísticas citadas no QUADRO 1.

As metáforas lingüísticas em si não revelam claramente que existe um conceito metafórico de amor subjacente, já que, conforme dissemos, elas são modos convencionais de falar sobre assuntos relacionados ao amor, como casamento, namoro e afetividade. Elas são metafóricas porque realizam mapeamentos sistemáticos entre esses domínios: há muitas expressões diferentes que relacionam amor e viagem de modo similar. Por exemplo, tanto 'esse namoro vai longe' quanto 'o casamento chegou ao fim' fazem mapeamentos sistemáticos entre amor e viagem: os amantes são os viajantes; o trajeto da viagem é a vida a dois; o final da viagem é o final do amor, etc. Em razão desses mapeamentos, que são implícitos e subconscientes, entendemos que tais expressões não são literais, isto é, não significam que o namoro está indo a um lugar concreto e distante, ou que o casamento chegou ao final de uma jornada real: o lugar e a jornada são expressões metafóricas.

$\mathrm{Na}$ análise das metáforas conceptuais, distinguimos entre um domínio fonte e um domínio alvo (LAKOFF; JOHNSON, 1980). O domínio fonte é aquele do qual retiramos as informações para entender o domínio alvo. No caso de AMOR É VIAGEM, o domínio fonte é viagem, e o alvo é amor. O domínio alvo é tipicamente um conceito abstrato (amor, tempo, emoções, etc.).

Na análise das metáforas lingüísticas, discernimos dois componentes: o Veículo e o Tópico (CAMERON, 2003). O Veículo é o elemento metaforizado, e o Tópico é o restante da expressão. Por exemplo, em 'esse namoro vai longe', o Veículo é 'vai longe', enquanto o Tópico é 'esse namoro'.

Uma das críticas que sofre a Teoria da Metáfora Conceptual é a falta de atenção às metáforas lingüísticas (CAMERON, 2003; DEIGNAN, 2005); o foco dominante dos estudiosos da área é o aspecto cognitivo do funcionamento das metáforas na mente. Contudo, sem as metáforas lingüísticas, as metáforas conceptuais não existiriam; por isso, é preciso

\footnotetext{
${ }^{6}$ As metáforas conceptuais são grafadas, por convenção, em fonte versalete ('small (caps').
} 
entender como as metáforas lingüísticas aparecem na linguagem autêntica. Para isso, é fundamental incorporar a Lingüística de Corpus aos estudos da metáfora, pois ela permite que se observe a língua realmente usada na interação humana, escrita e falada, e que se dê conta da abundância de linguagem que existe naturalmente no cotidiano, incluindo aí um evento comunicativo específico como os debates transmitidos por TV entre os presidenciáveis.

\section{Lingüística de Corpus}

A Lingüística de Corpusé uma área que investiga a língua em uso, tanto escrita quanto falada, registrada em formato de arquivo de computador. Um corpus é uma coletânea de textos ou transcrições de fala coletados criteriosamente para a pesquisa lingüística e salvos em formato eletrônico. O fato de os dados estarem inscritos em formato eletrônico suscita outra característica chave da Lingüística de Corpus: o emprego de computadores para a análise dos dados.

Ao contrário dos estudos da metáfora, que remontam à Grécia Antiga, a Lingüística de Corpus é uma vertente nova dos estudos lingüísticos. Ela surgiu em paralelo com o desenvolvimento dos computadores digitais; os primeiros estudos de corpora (plural de corpus) eletrônicos surgiram nos anos de 1960 (SINCLAIR, 1966).

A maioria dos estudos de Lingüística de Corpus atuais parte da observação da freqüência e da associação de palavras. A freqüência (alta ou baixa) de uma palavra na linguagem é vista pelos lingüistas de corpus como um aspecto constitutivo da palavra, e não apenas como um elemento acessório ou acidental. Palavras mais freqüentes são, em geral, as preferidas do falante e possuem relação com a sua ideologia, intenções, formalidade, escolaridade e o tópico do discurso, entre outros. A freqüência das palavras ainda nos permite entender diferenças e semelhanças entre os variados gêneros que compõem a comunicação humana, a relação marcado / não marcado, o nível de tecnicidade, a distinção entre escrita e fala e o contraste entre norma e uso, por exemplo. Além disso, a freqüência das palavras, se monitorada ao longo do tempo num corpus adequado, pode nos revelar, entre outras coisas, o aprendizado de um aluno ou até mesmo as mudanças sutis, mas inexoráveis, que sofre a linguagem.

A Lingüística de Corpus se preocupa também com a questão da associação entre palavras. É sabido que as palavras não se ligam no discurso de modo aleatório, mas obedecem, entre outros aspectos, ao assunto, 
intenções, subjetividade do falante, gênero do discurso, etc. Porém, os estudos de Lingüística de Corpus também revelam que as palavras se ligam umas às outras de modo sistemático, formando padrões. Alguns desses padrões são relativamente estáticos, como os ditados ('água mole em pedra dura, (...)') e os termos técnicos e científicos ('contração miocárdica'), e são facilmente percebidos como uma unidade formada por muitas palavras (ou multipalavra). Contudo, a Lingüística de Corpus mostra que a linguagem é inteiramente feita de padrões, dos mais diversos tamanhos, que se interligam e formam o fluxo da fala e da escrita (BIBER; CONRAD, 1999; HUNSTON, 2002). Por exemplo, neste parágrafo temos os padrões 'mostra que', que possui uma freqüência de 1,5 milhão na Web (segundo o Google), 'que a linguagem' (com 110 mil ocorrências) e 'totalmente feita' (438 ocorrências). Esses padrões geralmente passam despercebidos na fala ou escrita fluentes, e são apenas notados quando há algum tipo de quebra na expectativa mútua criada entre eles - por exemplo, se em vez de 'totalmente feita' disséssemos 'globalmente feita', teríamos uma quebra de padrões, pois essa combinação é possível, mas pouco provável (não ocorre uma vez sequer na Web). 'Globalmente', por sua vez, forma padrão com 'estável' (50 ocorrências) e com 'distribuído' (27 ocorrências).

Essas ligações interna (em cada padrão) e externa (entre os diferentes padrões) são de natureza probabilística e não normativa. Ou seja, as palavras tendem a se unir para formar padrões com base no uso lingüístico, que consagra certas formas e rejeita outras, e não por exigência de uma norma prescritiva. Não há nada nas regras gramaticais que impeça alguém de usar a combinação 'globalmente feita'; mesmo assim, ela é preterida pelos falantes, que preferem 'totalmente' ou 'inteiramente feita'.

O uso dos padrões é quase sempre automatizado e, portanto, subconsciente (WRAY, 2002), já que não há tempo nem capacidade cognitiva na fala e escrita correntes para premeditar o uso de cada padrão. Conseqüentemente, um bom orador ou escritor é aquele que sabe lidar com as probabilidades embutidas nos padrões para se expressar fluentemente, de tal modo que sua escolha de palavras e padrões vá ao encontro das expectativas do seu interlocutor (desde que a sua intenção seja essa).

Portanto, no estudo dos debates entre os candidatos a presidente, foi importante verificar os padrões de uso de cada presidenciável, para podermos notar as metáforas lingüísticas e, a partir delas, encontrar as metáforas conceptuais que revelaram como cada candidato pensa. Esses procedimentos são detalhados na seção seguinte. 


\section{Procedimentos de análise}

Nesta pesquisa, coletamos um corpus eletrônico formado por dois debates entre Luís Inácio Lula da Silva e Geraldo Alckmin, pelo segundo turno das eleições presidenciais de 2006: o do SBT (o segundo de uma série de quatro, transmitido em 19/10/2006) e o da Rede Globo (o último da série, veiculado em 27/10/2006). A transcrição dos debates foi colhida da Internet, do sítio do colunista Jorge Bastos Moreno (http://oglobo.globo.com/blogs/ moreno). Esses dois debates eram os únicos cuja transcrição estava disponível on-line, e foram escolhidos porque representam o universo dos debates da campanha presidencial do segundo turno de 2006, por duas razões. Primeiramente, porque essa seleção inclui o debate mais importante (o da Rede Globo, que teve a maior audiência, com 38 pontos, ${ }^{7}$ e o maior destaque, por ter acontecido no último dia permitido para a realização da campanha) e o menos importante (o do SBT, que teve a menor audiência, com 11 pontos percentuais, e o menor destaque, pois apareceu na segunda posição na série). Cremos que os candidatos e sua equipe de assessores estavam conscientes da importância relativa a cada debate, e participaram de modo condizente. Em segundo lugar, porque eles representam as duas dinâmicas que dominaram os debates. O do SBT seguiu o formato tradicional (assim como o da Band e o da Record), com perguntas e respostas do moderador e dos candidatos, enquanto o da Globo inovou, com perguntas colocadas pela platéia por meio de sorteio feito no palco pelos candidatos.

Depois de coletado, o corpus foi processado por uma série de scripts em Unix Shell, desenvolvidos pelo autor, a fim de transformar os arquivos em formato de texto simples ('txt'), extrair as falas dos dois candidatos e salvá-las em arquivos separados. Isso criou, na verdade, dois sub-corpora, correspondendo a cada um dos debatedores, conforme ilustra o QUADRO 2.

\footnotetext{
7 As informações sobre audiência são do sítio http://blog.estadao.com.br/blog/ padiglione $/$ ?cat $=202$.
} 
QUADRO 2

Dimensões docorpus

\begin{tabular}{|l|c|c|}
\hline Sub-corpus & Itens (tokens) & Formas (types) \\
\hline Lula & 11226 & 2048 \\
Alckmin & 10259 & 1941 \\
Total & 21485 & - \\
\hline
\end{tabular}

O quadro distingue itens e formas. Em cada sub-corpus, itens dão a totalidade de palavras ditas por cada candidato, enquanto formas indicam o número de vocábulos diferentes que cada um empregou.

O quadro mostra que Lula enunciou uma quantidade maior de palavras do que Alckmin (967 itens a mais). Devido ao fato de os candidatos terem tido tempos iguais para responder e de terem usado totalmente $\mathrm{o}$ tempo que lhes foi permitido para cada resposta, essa diferença parece indicar ritmos de fala distintos dos candidatos: Lula teria um ritmo mais acelerado de fala, e Alckmin, menos. Outra diferença é no tamanho do vocabulário de cada um: Lula exibiu um vocabulário com 107 formas a mais.

Em seguida, cada sub-corpus foi analisado pelo Identificador de Metáforas (BERBER SARDINHA, no prelo), um programa on-line, desenvolvido pelo autor (disponível no sítio http://www2.lael.pucsp.br/ corpora), que fez uma triagem do vocabulário de cada corpuse indicou as palavras com maior probabilidade de uso metafórico. Dessas, foram retiradas as 250 palavras com maior propensão de uso metafórico e foram geradas concordâncias para cada uma delas, por meio de scripts criados pelo autor. Concordâncias são um instrumento utilizado na Lingüística de Corpus para estudar os padrões de uma palavra; elas dispõem a palavra (chamada de nódulo) no centro da página (ou da tela do computador) e permitem uma visualização eficiente da associação dessa palavra com as outras em seu entorno. As concordâncias foram, então, analisadas linha a linha, e para cada uma foi decidido se era um caso de metáfora lingüística. Caso o fôsse, o nódulo da concordância seria considerado um Veículo de uma metáfora lingüística. A metáfora lingüística foi então interpretada, sendo então proposta uma metáfora conceptual que a licenciasse.

Por fim, as metáforas conceptuais foram contadas dentro de cada sub-corpus e na totalidade dos sub-corpora. Foram conduzidas provas de Qui-Quadrado $\left(\div^{2}\right)$ para determinar se havia diferença estatística entre os candidatos, o que serviu para eliminar situações em que a diferença 
observada poderia ter acontecido por acaso, seja porque havia pouca diferença entre os candidatos (quatro ocorrências para um e duas para outro, por exemplo) ou porque havia baixa freqüência de ocorrência (uma ou duas instâncias contra nenhuma, por exemplo).

No caso das metáforas conceptuais individuais, para cada uma foi montada uma tabela de contingência $2 \times 2$, segundo o modelo ilustrado na TAB. 1.

TABELA 1

Modelo de tabela de contingência para cada metáfora conceptual

\begin{tabular}{l|l|l}
\hline & Lula & Alckmin \\
\hline $\begin{array}{l}\text { Ocorrências da metáfora } \\
\text { conceptual em questão }\end{array}$ & A & B \\
$\begin{array}{l}\text { Ocorrências de outras } \\
\text { metáforas conceptuais }\end{array}$ & $\mathrm{C}=129-\mathrm{A}$ & $\mathrm{D}=144-\mathrm{B}$ \\
Total & 129 & 144 \\
\hline
\end{tabular}

Por exemplo, no caso da metáfora conceptual a ECONOMIA É um ORGANISMO, que teve 47 ocorrências para Lula (A) e 36 para Alckmin (B), o cálculo foi o seguinte: $\mathrm{C}=129-47=82 ; \mathrm{D}=144-26=108$. Com esses valores, a prova de $\div$ retorna um valor de 4,5 , que é significante $(p<0,05)$. Isso indica que Lula usou significativamente mais vezes essa metáfora do que Alckmin. Os resultados completos referentes a essa comparação aparecem na TAB. 6.

\section{Resultados}

Em primeiro lugar, verificamos se houve diferença quantitativa de uso metafórico entre os dois candidatos. Nesta parte do trabalho, enfocamos a quantidade de uso global de metáfora, sem distinguir quais metáforas foram usadas.

\footnotetext{
candidatos.

A TAB. 2 mostra a quantidade de metáforas usadas pelos dois
} 
TABELA 2

Quantidade de metáforas

\begin{tabular}{l|c|c}
\hline Candidato & Metáforas conceptuais & Metáforas lingüísticas \\
\hline Lula & $26(46 \%)$ & $129(47 \%)$ \\
Alckmin & $31(54 \%)$ & $144(53 \%)$ \\
Total & 57 & 273 \\
\hline
\end{tabular}

Como se percebe, houve quase um empate entre os candidatos. Essa diferença não é estatisticamente significativa $(\div 2=0,05$; NS), o que implica dizer que não há diferença real entre o uso de metáfora dos dois candidatos.

Com esses números, pudemos calcular a freqüência do emprego de metáforas lingüísticas, conforme mostra a TAB. 3.

TABELA 3

Freqüência de uso de metáforas lingüísticas

\begin{tabular}{l|c|c|c}
\hline Candidato & $\begin{array}{l}\text { Metáforas } \\
\text { lingüísticas (A) }\end{array}$ & Palavras (B) & $\begin{array}{l}\text { Média por 100 } \\
\text { palavras (B / A x 100) }\end{array}$ \\
\hline Lula & $129(47 \%)$ & 11226 & 1,15 \\
Alckmin & $144(53 \%)$ & 10259 & 1,40 \\
Total & 273 & 21550 & 1,27 \\
\hline
\end{tabular}

Conforme mostra a TAB. 3, Lula usou em média 1,15 metáforas a cada 100 palavras (ou uma metáfora a cada 87 palavras), enquanto Alckmin utilizou 1,4 metáforas por 100 palavras (ou uma a cada 71 palavras). A diferença observada é bastante pequena e, por isso, não é estatisticamente significativa $\left(\div^{2}=0 ; \mathrm{NS}\right)$. Como cada metáfora lingüística é geralmente composta de mais de uma palavra, a freqüência de uso efetivo é provavelmente maior. Em relação à freqüência de uso por frase, Lula utilizou em média 1,4 metáfora por frase, enquanto Alckmin, 1,44. Não há, portanto,

\footnotetext{
${ }^{8}$ Vale notar que o fato de as metáforas lingüísticas serem compostas por mais de uma palavra não deve alterar esse resultado, visto que as metáforas lingüísticas normalmente não ultrapassam a barreira das frases. Sendo assim, o fato de uma metáfora lingüística comportar mais de uma palavra não mudará a freqüência com que ocorre na frase, visto que as demais palavras que a formam provavelmente estarão contidas na mesma frase.
} 
diferença entre os dois candidatos no tocante à freqüência do uso de metáforas lingüísticas.

Entretanto, pode ter havido uma diferença entre os candidatos no tocante ao emprego de metáforas conceptuais diferentes, isto é, metáforas que foram usadas somente por um dos candidatos, e de metáforas compartilhadas, isto é, metáforas que foram usadas por ambos os candidatos. Essa contagem pode ser feita de dois modos: por meio de types ou tokens. Um type de metáfora conceptual corresponde a uma instância, não importando se foi usada uma ou mais vezes; uma mesma metáfora conceptual foi contada apenas uma vez. Já um token de metáfora conceptual indica uma ocorrência efetiva de metáfora conceptual; uma mesma metáfora conceptual foi contada tantas vezes quantas ela tenha ocorrido, o que significa que esse número coincide com o total de metáforas lingüísticas.

A TAB. 4 mostra os números referentes à contagem de types.

TABELA 4

Types de metáforas conceptuais

\begin{tabular}{l|c|c}
\hline Candidato & $\begin{array}{c}\text { Types de metáforas } \\
\text { conceptuais diferentes }\end{array}$ & $\begin{array}{c}\text { Types de metáforas } \\
\text { conceptuais compartilhadas }\end{array}$ \\
\hline Lula & $4(57 \%)$ & $22(44 \%)$ \\
Alckmin & $3(43 \%)$ & $28(56 \%)$ \\
Total & 7 & 50 \\
\hline
\end{tabular}

A diferença entre os dois candidatos não é estatisticamente significativa $\left(\div^{2}=0,4 ;\right.$ NS $)$, o que indica que não houve diferença entre os candidatos no tocante ao uso de metáforas conceptuais diferentes ou compartilhadas.

A TAB. 5 mostra os resultados referentes aos tokens de metáforas conceptuais.

TABELA 5

Tokens de metáforas conceptuais

\begin{tabular}{l|c|c}
\hline Candidato & $\begin{array}{c}\text { Tokens de metáforas } \\
\text { conceptuais compartilhadas }\end{array}$ & $\begin{array}{c}\text { Tokens de metáforas } \\
\text { conceptuais diferentes }\end{array}$ \\
\hline Lula & $64(57 \%)$ & $65(40 \%)$ \\
Alckmin & $48(43 \%)$ & $96(60 \%)$ \\
Total & 112 & 161 \\
\hline
\end{tabular}


A diferença entre os tokens de metáfora conceptual é estatisticamente significativa $\left(\dot{\div}^{2}=7,45 ; \mathrm{p}<0,01\right)$. Isso indica que Lula usou mais vezes as mesmas metáforas conceptuais compartilhadas ( $57 \%$ do total); Alckmin, por sua vez, variou mais suas metáforas conceptuais (60\% do total).

Em suma, a análise quantitativa mostrou que os dois candidatos foram bastante parecidos nos debates em relação ao uso de metáforas. Ambos usaram uma quantidade similar de metáforas, com a mesma freqüência, nas suas participações. A única diferença significativa entre os candidatos foi em relação ao emprego de metáforas iguais ou diferentes das do seu oponente. Lula empregou mais vezes as mesmas metáforas que Alckmin; já Alckmin utilizou mais vezes as suas próprias metáforas.

Passamos agora aos resultados referentes ao uso de cada metáfora conceptual. A TAB. 6 mostra esses resultados.

TABELA 6

Uso de cada metáfora conceptual

(com ordenação descendente pela coluna 'total')

\begin{tabular}{|c|c|c|c|c|c|c|c|}
\hline & Metáfora & Lula & Alck. & Tot. $^{9}$ & Diferença $^{10}$ & $\dot{\div}^{2}$ & $p^{11}$ \\
\hline$\overline{1 .}$ & A ECONOMIA É UM ORGANISMO & 47 & 36 & 83 & $13.25 \%$ & 4,5 & $<0,05$ \\
\hline 2. & COMPREENDER É VER & 9 & 35 & 44 & $59.09 \%$ & 14,7 & $<0,001$ \\
\hline 3. & BOM É PARA BAIXO & 0 & 19 & 19 & $100.00 \%$ & 18,3 & $<0,001$ \\
\hline 4. & BOM É GRANDE & 13 & 4 & 17 & $52.94 \%$ & 6,4 & $<0,025$ \\
\hline 5. & BOM É PARA CIMA & 12 & 1 & 13 & $84.62 \%$ & 11,3 & $<0,001$ \\
\hline 6. & RUIM É GRANDE & 3 & 7 & 10 & $40.00 \%$ & 1,2 & NS \\
\hline 7. & O TEMPO É UM OBJETO ESTACIONÁRIO & 9 & 0 & 9 & $100.00 \%$ & 10,5 & $<0,01$ \\
\hline 8. & RUIM É PARA CIMA & 4 & 2 & 6 & $33.33 \%$ & 0,9 & NS \\
\hline 9. & O TEMPO É UM RECIPIENTE & 5 & 0 & 5 & $100.00 \%$ & 5,7 & $<0,25$ \\
\hline 10. & GOVERNO É UM RECIPIENTE & 0 & 4 & 4 & $100.00 \%$ & 3,6 & NS \\
\hline 11. & MUDANÇA É UMA VIAGEM & 0 & 4 & 4 & $100.00 \%$ & 3,6 & NS \\
\hline 12. & BOM É FORTE & 3 & 0 & 3 & $100.00 \%$ & 3,4 & NS \\
\hline
\end{tabular}

\footnotetext{
${ }^{9}$ Essa coluna registra a soma dos dois candidatos.

${ }^{10}$ Essa coluna mostra a diferença de ocorrências de metáforas conceptuais entre os dois candidatos, em porcentagem. No caso da primeira metáfora, temos (47 - 36) $/ 83 \times 100=13,25$.

${ }^{11}$ Essa coluna exibe o valor crítico de $p$ para $\mathrm{o} \div{ }^{2}$ com grau de liberdade $=1$. A sigla NS representa um valor de $p$ não significativo.
} 


\begin{tabular}{|c|c|c|c|c|c|c|}
\hline Metáfora & Lula & Alck. & Tot. $^{9}$ & Diferença $^{10}$ & $\dot{\div}^{2}$ & $p^{11}$ \\
\hline 13. A ECONOMIA É UMA CONSTRUÇÃO & 3 & 0 & 3 & $100.00 \%$ & 3,4 & NS \\
\hline 14. A ECONOMIA É UM LÍQUIDO & 1 & 2 & 3 & $33.33 \%$ & 0,2 & NS \\
\hline 15. TER AFINIDADE É TER CONEXÃO FÍSICA & 0 & 3 & 3 & $100.00 \%$ & 2,7 & NS \\
\hline 16. A ECONOMIA É UM RECIPIENTE & 2 & 0 & 2 & $100.00 \%$ & 2,3 & NS \\
\hline 17. A GOVERNO É UMA CONSTRUÇÃO & 2 & 0 & 2 & $100.00 \%$ & 2,3 & NS \\
\hline 18. A PREVIDÊNCIA SOCIAL É UM RECIPIENTE & 2 & 0 & 2 & $100.00 \%$ & 2,3 & NS \\
\hline 19. O TRABALHO É ESPORTE & 2 & 0 & 2 & $100.00 \%$ & 2,3 & NS \\
\hline 20. USAR É ENTRAR & 2 & 0 & 2 & $100.00 \%$ & 2,3 & NS \\
\hline 21. ALGO BOM É UMA MINIATURA & 0 & 2 & 2 & $100.00 \%$ & 1,8 & NS \\
\hline 22. O AUXÍLIO GOVERNAMENTAL & & & & & & \\
\hline É UM INSTRUMENTO & 0 & 2 & 2 & $100.00 \%$ & 1,8 & NS \\
\hline 23. CANAL & 0 & 2 & 2 & $100.00 \%$ & 1,8 & NS \\
\hline 24. DESMATAMENTO É ESPORTE & 0 & 2 & 2 & $100.00 \%$ & 1,8 & NS \\
\hline 25. PROCURAR SOLUÇÃO É UMA VIAGEM & 0 & 2 & 2 & $100.00 \%$ & 1,8 & NS \\
\hline 26. O PROGRESSO É UMA VIAGEM & 0 & 2 & 2 & $100.00 \%$ & 1,8 & NS \\
\hline 27. A VIDA É UMA VIAGEM & 0 & 2 & 2 & $100.00 \%$ & 1,8 & NS \\
\hline 28. CRIAR É CONSTRUIR & 1 & 0 & 1 & $100.00 \%$ & 1,1 & NS \\
\hline 29. A HISTÓRIA É UMA VIAGEM & 1 & 0 & 1 & $100.00 \%$ & 1,1 & NS \\
\hline 30. INVESTIMENTO É JOGO DE AZAR & 1 & 0 & 1 & $100.00 \%$ & 1,1 & NS \\
\hline 31. O ORÇAMENTO É UM RECIPIENTE & 1 & 0 & 1 & $100.00 \%$ & 1,1 & NS \\
\hline 32. ORÇAMENTO É UMA BALANÇA & 1 & 0 & 1 & $100.00 \%$ & 1,1 & NS \\
\hline 33. O PAÍ́S É UMA MÁQUINA & 1 & 0 & 1 & $100.00 \%$ & 1,1 & NS \\
\hline 34. PLANOS ECONÔMICOS SÃO OBJETOS & 1 & 0 & 1 & $100.00 \%$ & 1,1 & NS \\
\hline 35. A POBREZA É UM ORGANISMO & 1 & 0 & 1 & $100.00 \%$ & 1,1 & NS \\
\hline 36. O PRESIDENTE É UM ATOR & 1 & 0 & 1 & $100.00 \%$ & 1,1 & NS \\
\hline 37. VER É COMPREENDER & 1 & 0 & 1 & $100.00 \%$ & 1,1 & NS \\
\hline 38. BOM É LARGO & 0 & 1 & 1 & $100.00 \%$ & 0,9 & NS \\
\hline 39. BOM É RÁPIDO & 0 & 1 & 1 & $100.00 \%$ & 0,9 & NS \\
\hline 40. A ECONOMIA SÃO CONDIÇÕES & & & & & & \\
\hline CLIMÁTICAS & 0 & 1 & 1 & $100.00 \%$ & 0,9 & NS \\
\hline 41. ECONOMIA É ESPORTE & 0 & 1 & 1 & $100.00 \%$ & 0,9 & NS \\
\hline 42. O ENSINO É UM OBJETO & 0 & 1 & 1 & $100.00 \%$ & 0,9 & NS \\
\hline 43. O GOVERNO É UM ORGANISMO & 0 & 1 & 1 & $100.00 \%$ & 0,9 & NS \\
\hline 44. IMAGEM DE CENTRO E PERIFERIA & 0 & 1 & 1 & $100.00 \%$ & 0,9 & NS \\
\hline 45. IMPOSTOS SÃO OBJETOS & 0 & 1 & 1 & $100.00 \%$ & 0,9 & NS \\
\hline
\end{tabular}


(continuação)

\begin{tabular}{l|r|r|r|r|r|r}
\hline Metáfora & Lula & Alck. & Tot. $^{9}$ & Diferença $^{10}$ & $\dot{\div}^{2}$ & $p^{11}$ \\
\hline 46. A OPORTUNIDADE É UM OBJETO & & & & & & \\
EM MOVIMENTO & & 1 & 1 & $100.00 \%$ & 0,9 & NS \\
47. O PLANEJAMENTO É UMA AGENDA & & & & & & \\
DE COMPROMISSOS & 0 & 1 & 1 & $100.00 \%$ & 0,9 & NS \\
48. REALIDADE É UMA VIAGEM & 0 & 1 & 1 & $100.00 \%$ & 0,9 & NS \\
49. A RESPONSABILIDADE É UM OBJETO & 0 & 1 & 1 & $100.00 \%$ & 0,9 & NS \\
50. RUIM É PARA BAIXO & 129 & 144 & & & 0,9 & NS \\
Total &
\end{tabular}

A TAB. 2 mostra que, entre as 50 metáforas conceptuais empregadas pelos debatedores, há apenas sete em que não há empate estatístico (indicados por NS na coluna 'p'). Podemos chamá-las de metáforas distintivas, pois distinguem significativamente os candidatos. Devido à sua importância, restringimos nossa análise a elas no restante do trabalho. O GRÁFICO 1 resume as ocorrências das metáforas distintivas.

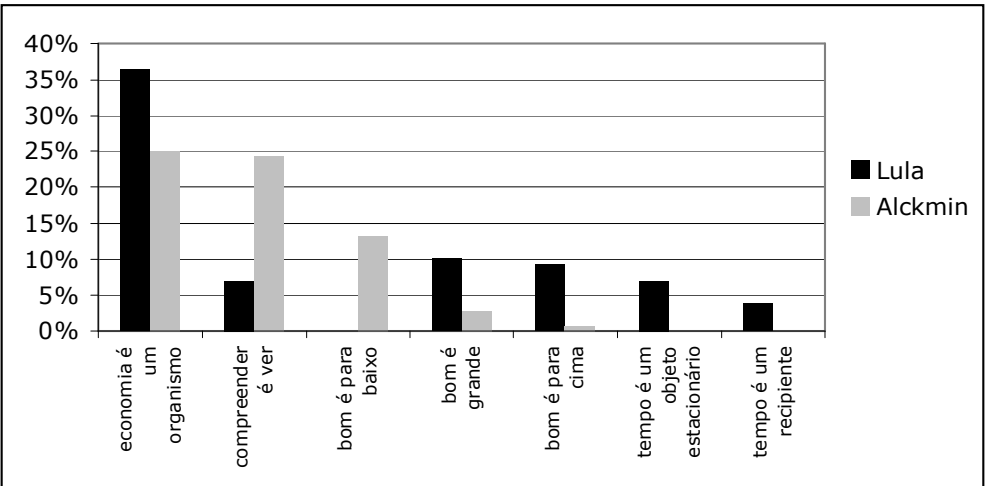

GRÁFICO 1-Metáforas distintivas (as porcentagens referem-se ao total de metáforas de cada candidato)

Como se percebe no GRA. 1, Lula usou mais freqüentemente cinco metáforas conceptuais:

1. a economia é um organismo

2. bom é grande

3. bom é para cima

4. o tempo é um objeto estacionário

5. o tempo é um recipiente 
Já Alckmin usou mais freqüentemente apenas duas metáforas:

1. compreender é ver

2. bom é para baixo

Isso mostra que:

- Lula empregou uma gama maior de metáforas distintivas;

- o conjunto de metáforas distintivas de Lula é mais coerente com temas de campanha e de governo, conforme colocados no programa de governo do Partido dos Trabalhadores (PT, 2006), visto que: (1) as metáforas da economia ligam-se ao tema do desenvolvimento, que foi central na campanha ('o nome do meu segundo mandato será desenvolvimento', PT, 2006, p. 3; 'caberá ao segundo mandato avançar mais aceleradamente no rumo desse novo ciclo de desenvolvimento', PT, 2006, p. 5); (2) as metáforas orientacionais (BOM É GRANDE, BOM É PARA CIMA) referem-se ao sucesso (do ponto de vista do partido) do primeiro mandato ('O Governo Lula enfrentou exitosamente os [...] desafios. [...] crescimento e formalização do emprego, aumento da massa salarial' (PT, 2006, p. 6); 'aumento dos investimentos', PT, 2006, p. 7; 'grande potencial brasileiro', PT, 2006, p. 18); (3) as metáforas do tempo relacionam-se à questão da gradual superação das dificuldades 'herdadas' dos governos anteriores ('o Governo Lula viu-se desde o início diante de um duplo desafio' (PT, 2006, p. 6); 'as eleições de outubro de 2006 serão um confronto entre passado e futuro' (PT, 2006, p. 7).

- o conjunto de metáforas distintivas de Alckmin é menos coerente com a mensagem da oposição: não há referências à corrupção e ao baixo crescimento, que foram temas centrais de campanha (segundo Alckmin, 'a corrupção espanta crédito, espanta investimento, desestimula a todos, cria um clima horrível porque não há segurança nas instituições', Veja, 2006).

A seguir, passamos a um exame mais detalhado do uso de cada metáfora distintiva, seguindo a ordem mostrada na TAB. 6, isto é, pelo total de usos.

A metáfora distintiva dominante nos debates foi A ECONOMIA É UM ORGANISMO. Essa metáfora em geral tem a função de tornar a economia, que é uma atividade humana, em um processo do mundo natural, sobre o qual o homem não tem poder. Ou seja, ela nos faz pensar que a economia cresce ou se retrai por vontade própria, como um organismo que cresce seguindo as leis da natureza, e não por mérito ou culpa de alguém ou de um partido político. 
Assim, ao apagar a agência humana (CHARTERIS-BLACK, 2004), de certo modo ela funciona para eximir a responsabilidade dos que possuem $\mathrm{O}$ comando da economia. Como se vê, ela é um aliado natural do presidente Lula, que esteve sob ataque cerrado da oposição por não ter sido capaz de fazer com que a economia crescesse mais, pois, como vimos, essa metáfora não serve diretamente para atribuir culpa a alguém pelos desandos da economia, já que esta cresce (ou se retrai) seguindo seu próprio ritmo.

Lula a empregou geralmente para afirmar que certos segmentos da economia brasileira cresceram, que o crescimento atual não é o ideal, e que é uma questão de tempo até que cresça em definitivo. A Concordância 1 ilustra esses usos.

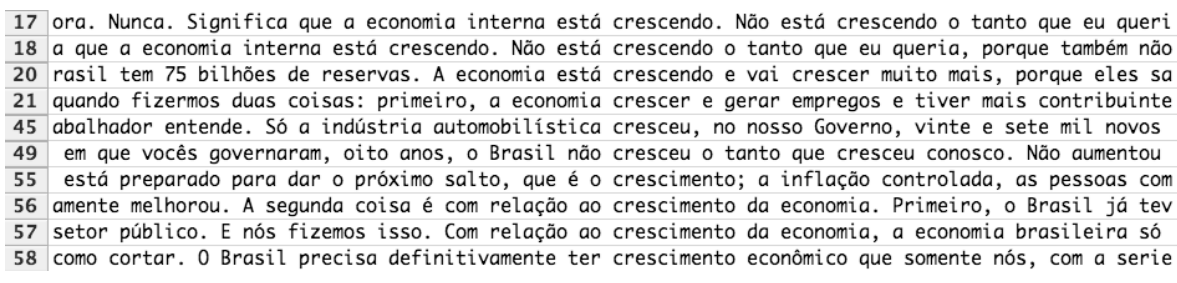

Concordância 1 - Alguns usos de A ECONOMIA É UM ORGANISMO por Lula

Alckmin, por sua vez, empregou essa metáfora para dizer que o país cresceu pouco, que precisa crescer mais, e que o crescimento não acontecerá sob o comando de Lula. Novamente, essa metáfora não é a mais adequada para atingir o presidente, pois ela não identifica claramente os responsáveis pela condução da economia. A Concordância 2 mostra algumas dessas ocorrências.

21 ltimo. Eu não estou satisfeito com isso. 0 Brasil crescendo $2 \%$ não vai diminuir pobreza, não vai red 23 scer menos que o Paraguai, que a Bolívia, o mundo crescer 5\% e o Brasil crescer 2\%, a Argentina cres

24 uai, que a Bolívia, o mundo crescer 5\% e o Brasil crescer 2\%, a Argentina crescer 9\%, o Brasil 2\%! Q

25 ndo crescer 5\% e o Brasil crescer 2\%, a Argentina crescer 9\%, o Brasil 2\%! Quando o Lula entrou, tin

28 trabalhar nessa questão, para, primeiro o Brasil crescer, o Brasil pode crescer 5, 6\% do PIB, não $\mathrm{h}$

29 o, para, primeiro o Brasil crescer, o Brasil pode crescer 5, 6\% do PIB, não há razäo para não cresce

31 ha o Brasil ser o penúltimo da América Latina, só crescer mais que o Haiti. Por que nós somos conden

49 nos que o Paraguai, menos que a Bolívia, $2 \%$ só em crescimento, a informalidade é muito grande, mais

51 é país que cresce. Não podemos jogar a agenda do crescimento fora.

icamente não saindo do lugar, ficando parado, com crescimento de apenas $2 \%$. Eu quero dizer do que eu

Concordância 2 - Alguns usos de A ECONOMIA É UM ORGANISMO por Alckmin

A segunda metáfora mais distintiva é COMPREENDER É VER, que foi mais empregada por Alckmin. Essa metáfora é normalmente usada para concretizar o ato da compreensão, fazendo com que algo que seja mais claro ou visível seja tido como mais compreensível. Alckmin a empregou 
geralmente para dizer que sua mensagem era palpável e clara e, portanto, compreensível. Ela apareceu quase sempre por meio do imperativo 'olha'. A Concordância 3 mostra alguns desses usos.

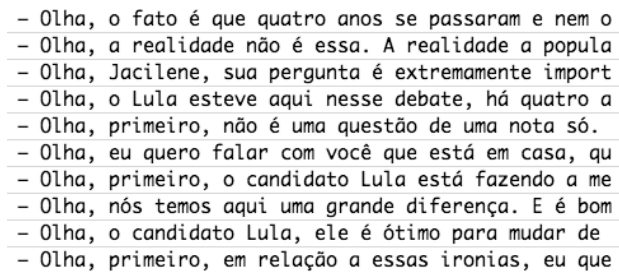

Concordância 3 - Alguns usos de COMPREENDER É VER por Alckmin

Lula usou essa metáfora geralmente para ironizar o seu oponente, conforme mostra a Concordância 4.

- Olha, uma coisa que precisa ficar clara neste debat
- Olha, falando com uma pessoa que sabe da irresponsa
- Olha, o Alckmin adora brincar com números, possivel
- Olha, uma coisa que precisa ficar clara neste deba
- Olha, você deve conhecer que grande parte das casa
- Olha, veja que interessante. Ele falou de 220 mil
- Olha, primeiro, qualquer brasileiro sabe que $90 \%$ d
- Olha, eu acho que o Alckmin se faz de näo entendid
- Olha, é muito fácil falar, não é, Alckmin? É difíc

Concordância 4 - Todos os usos de COMPREENDER É VER por Lula

A terceira metáfora mais distintiva é BOM É PARA BAIXo, que foi empregada apenas por Alckmin. Essa metáfora é chamada de direcional, pois relaciona o sentido de um movimento com um juízo de valor. Na cultura ocidental, geralmente o sentido 'para cima' está relacionado com um bom estado de coisas. Por exemplo, quando dizemos 'subir na vida', 'pensar alto' ou 'alta qualidade', estamos nos referindo a melhorar de vida, ter ambições e fazer bem um trabalho. Por sua vez, a direção 'para baixo' indica coisas ruins: 'descer para o nível de alguém', 'cair em depressão', 'baixaria'. Assim, a metáfora BOM É PARA BAIXO é até certo ponto contra-sensual, pois inverte a direção canônica da metáfora. Ela funciona para falar de coisas cujo crescimento é ruim, como inflação, violência e criminalidade, por exemplo. Desse modo, essa metáfora traz por si só uma conotação negativa, pois está associada a problemas sociais ou econômicos. Isso se encaixa na estratégia de Alckmin, que era justamente a de levantar os problemas do governo e propor mudanças. Em quase todas as ocorrências, ele a empregou para falar da necessidade de reduzir impostos, conforme mostra a Concordância 5. 


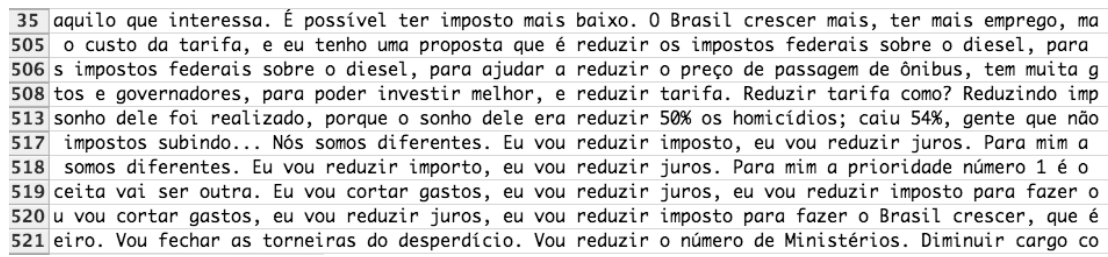

Concordância 5-Alguns usos de BOM É PARA BAIXO por Alckmin

A quarta metáfora mais distintiva é BOM É GRANDE (Concordância G). Ela funciona atribuindo um valor positivo a alguma coisa devido ao seu tamanho. Assim, um 'grande amigo' é um 'bom amigo', 'grande pai' 'é um bom pai', e 'grande dia' é um 'bom dia'. Como 'amigo', 'pai' e 'dia' são concretos, a metáfora atua nos elementos que os tornam bons, que podem ser, entre outros, a lealdade (amigo), a sabedoria (pai) e a felicidade (dia). Muitas vezes, essa metáfora concretiza algo abstrato, pois somente coisas concretas possuem dimensão literal. Assim, 'grande aumento de salário' significa um bom aumento, etc.

Lula empregou essa metáfora para falar de coisas diversas, mas, em geral, os tópicos envolvidos estão relacionados à economia, tais como o tamanho da economia, as verbas liberadas por seu governo e o salário mínimo.

380 bertura extraordinária. Ela tem uma cobertura tão grande que na Constituição de 1988 nós incluímos 6 382 o Paraguai! A economia brasileira é uma economia grande, sólida. Foi quebrado este País duas vezes 384 rimeira vez que o BNDES destina uma parcela muito grande do dinheiro disponível que ele tem para aju 386 e país é financiada pela Caixa Econômica Federal, grande parte, e $73 \%$ das quase 900 mil casas , 588 387 profissional assinada. Até 1980 , nós tínhamos uma grande maioria de trabalhadores brasileiros com ca 389 l comercializado e o Brasil vai se transformar na grande potência energética do mundo; proteção ao 389 comercializado e o Brasil val se transformar na grande potencia energetica do mundo; proteçâo ao 641 cio e 10 bilhos para a aricultura 75 biras 642 cordes; segundo, temos uma reserva de 75 bilhoes, maior do que a divida liquida publica brasileira; 643 líquida pública brasileira; terceiro, nós temos a maior geração de emprego dos últimos 10 anos; quar 644 aumento que nós demos ao salário mínimo, que é o maior dos últimos 30 anos, para os aposentados, sa

Concordância 6 - Alguns usos de BOM É GRANDE por Lula

Alckmin, por sua vez, utilizou-a com a finalidade de cobrar do presidente (pedindo 'maior empenho') e para falar a respeito da hospitalidade com que foi recebido e da rede hospitalar federal. Ou seja, foram usos difusos, que não se centraram em um tópico principal, ao contrário do que fez Lula com a economia. A Concordância 7 mostra esses usos.

247 ano, fui recebido da melhor maneira possível, com grande hospitalidade. Vi todos os brasis, percorri 249 e, é aquele para o qual o Governo precisa fazer o maior empenho. Maior empenho. Eu vou trabalhar nes 250 a o qual o Governo precisa fazer o maior empenho. Maior empenho. Eu vou trabalhar nessa questäo, par 256 do Rio de Janeiro, porque o Governo Federal tem a maior rede hospitalar federal no Rio de Janeiro. É

Concordância 7 - Todos os usos de BOM É GRANDE por Alckmin 
A quinta metáfora mais distintiva é BOM é PARA CIMA. Tendo sido dominada por Lula, serviu como contraponto a BOM É PARA BAIXO, exclusiva de Alckmin. BOM É PARA CIMA se presta para tratar de aspectos positivos, que se tornam bons ou melhores à medida que se avolumam. Assim, por exemplo, se alguém subiu na vida, cremos que seja uma mudança para melhor.

Lula explorou essa metáfora para se referir a aumentos de dotação orçamentária e do salário mínimo, conforme mostra a Concordância 8. Vale notar que o exemplo 8 da concordância é positivo, mesmo estando associado à inflação, pois trata-se de um aumento de salário que esteve acima do índice inflacionário.

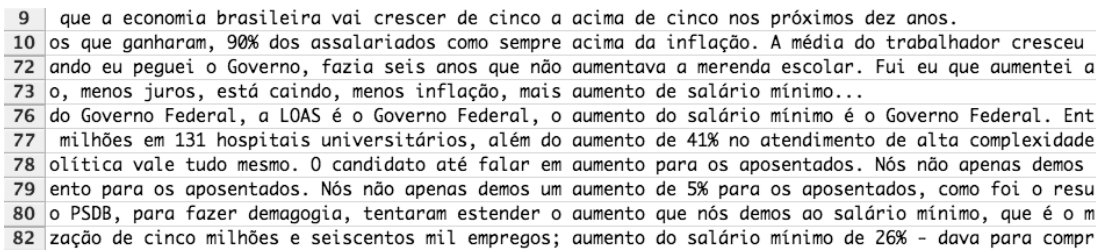

Concordância 8 - Alguns usos de BOM É PARA CIMA por Lula

Alckmin empregou essa metáfora apenas uma vez, para falar de transporte público, conforme ilustra a Concordância 9.

2 anarho do metrob. Eu vou investir no transporte de alta capacidade. Vou investir para valer: metrob, $t$

Concordância 9- O único uso de BOM É PARA CIMA por Alckmin

A sexta metáfora mais distintiva envolve a noção de tempo: TEMPO É UM OBJETO ESTACIONÁRIO. Essa metáfora conceitua o tempo como um objeto que tem uma extensão determinada, com começo, meio e fim. Dessa forma, podemos percorrer o tempo, marcar o início e o fim de eventos e calcular sua duração. Ela serve para dar concretude ao tempo, permitindo-nos prever o futuro, bem como racionalizar sobre o passado. Seus únicos usos foram feitos por Lula, que a empregou para falar de períodos de tempo próximos (como os anos do seu governo ou mesmo o tempo decorrido no debate) e distantes (como o século XIX ou governos anteriores), conforme mostra a Concordância 10.

207 a da enchente, normalmente no final do ano para o começo do ano. Eu posso te garantir que depois da
208 e perderam durante todo o século XX e perderam no começo do século XXI, porque nós vamos fazer acont
209 orque tem excesso de dólar no Brasil. Eu disse no começo, são 75 bilhões de dólares de reservas, coi
251 as. Ele construiu 59 mil casas. Ele está contando desde 94 , quando assumiu o Governo Mário Covas, ma
475 idade. Então, ele é o resultado do descaso que ao longo da história se teve com a distribuição de re
476 mente ter um crescimento sustentável num ciclo de longo prazo, gerando o desenvolvimento, gerando o
605 números. O desmatamento na Amazônia caiu 31 o ano passado e 30 esse ano, ou seja, no acumulado foram
606 ma. Quase tudo no interior. Vocês sabem que o ano passado foi aprovado no Congresso Nacional o prime
610 mpromisso năo deu um centavo. No orçamento do ano passado colocou 10 reais no orçamento apenas para
Concordância 10 - Todos OS uSOS de O TEMPO É UM OBJETO ESTACIONÁRIO por Lula 
A última metáfora distintiva é o TEMPO É UM RECIPIENTE. Ela serve para conceituar o tempo como um objeto fechado, em que podemos entrar, permanecer ou sair. Assim como a anterior, empresta uma dimensão espacial ao tempo, permitindo-nos falar, por exemplo, em 'no dia de hoje', 'na semana passada', 'entrar no verão', etc. Ela foi empregada exclusivamente por Lula, por meio da palavra 'hora', e serviu essencialmente a dois propósitos: criticar a oposição ('na hora de fazer projeto / votar / fazer pergunta [...] não fazem / votam / faz') ou afirmar que seu governo age na hora certa, conforme mostra a Concordância 11.

435 fossem vendidos de forma inadequada. Segundo, na hora de fazer o projeto, deveria o prefeito, junto 437 ntro do Congresso Nacional. Falam, falam, mas, na hora de votar, não votam.

439 ós fizemos aquilo que um governo tem que fazer na hora certa, com a precisão que precisava ser feita 440 dinheiro disponível para resolver os problemas na hora certa. É por isso que nós criamos o seguro ag 441

$$
\text { - Ele faz pergunta fora de hora. Ele, ao invés de responder, faz pergunta. }
$$

Concordância 11 - Todos os usos de o TEMPO É UM RECIPIENTE por Lula

\section{Conclusão}

A análise revelou que houve poucas diferenças entre os candidatos em relação ao emprego de metáforas. Ambos as usaram em quantidades parecidas. A principal diferença entre eles foi em relação à ênfase. Alckmin pulverizou suas metáforas: colocou em cena um número maior delas, mas com poucas ocorrências de cada. Lula foi mais seletivo e neutralizou o adversário, conseguindo concentrar seu discurso em metáforas mais condizentes com os seus propósitos.

Essa estratégia de Lula aponta novamente para o fato de ele ser um bom orador, que sabe se comunicar, principalmente com as camadas mais simples da sociedade. As regras do debate o impediram de fazer uso de suas metáforas favoritas, que são embutidas em longas narrativas. Mesmo assim, Lula soube usar o potencial persuasivo das metáforas para influenciar o eleitor, protegendo-se dos ataques do seu opositor e sublinhando aspectos positivos do seu governo, como o crescimento setorial da economia e do repasse de verbas para fins sociais. Conceituou a economia como uma criatura com vontade própria, que tem seu próprio ritmo de crescimento, esquivando-se, assim, da responsabilidade pelo mau desempenho econômico. Também atribuiu uma dimensão temporal e espacial à sua administração, contrastando-a com a de seus predecessores. Dominou o uso de metáforas que fazem juízo de valor, correlacionando-as a aspectos 
positivos (aumento do salário mínimo, da aposentadoria, da geração de emprego, etc.).

As metáforas que Alckmin dominou não foram condizentes com seu discurso. Deu muita ênfase à conceituação da economia como organismo, o que favoreceu o seu opositor (pois, como vimos, essa metáfora esconde a responsabilidade humana pela falha na condução da economia). Entretanto, precisamos reconhecer que o candidato tinha poucas alternativas, visto que não há maneiras eficientes de falar da economia sem usar vocabulário como 'crescimento' e 'geração', que são os modos convencionais de se referir à economia. Talvez a estratégia recomendável nesse caso fosse a da seletividade, como fez Lula: não seria o caso de evitar falar sobre a falta de crescimento da economia, mas dar menos ênfase ao fato.

A outra metáfora que Alckmin dominou nos debates (BOM É PARA BAIXO) talvez tenha causado nos telespectadores uma impressão negativa. Conforme mostramos, ela está associada à diminuição de problemas, o que implica falar constantemente sobre aspectos negativos da vida nacional. Aos ouvidos da população, isso pode ter soado como um excesso de reclamações sem propostas concretas de melhoria.

Chamou a atenção o fato de Alckmin não ter sido mais enfático nas metáforas sobre corrupção, que foi um tema dominante na campanha eleitoral. A palavra 'dinheiro', por exemplo, teve apenas nove usos metafóricos (19\%), entre 47 ocorrências nas suas falas. Conforme mostra a Concordância 12, a metáfora principal nesse caso foi A CORRUPÇão É UMA VIAGEM, que conceitua a movimentação e os desvios de dinheiro. A atribuição de culpa por essa movimentação suspeita ficou obscurecida, pois não foram explicitados vários mapeamentos, que poderiam ser, entre outros, os seguintes: Lula, como guia da viagem; governo, como veículo usado na viagem; estrada, como o rumo errado do país; corrupção, como um acidente fatal na estrada; povo, como passageiros viajando em direção a um desastre. 
CORRUPÇÃO É UMA VIAGEM

1 ? Trinta bilhões de reais. Desperdício, desvio de dinheiro, vampiros, sanguessugas, dinheiro do povo 2 tá ruim, a segurança está ruim e onde está indo o dinheiro. 0 brasileiro trabalha janeiro, fevereiro 3 Olha, quando o candidato Lula falou de onde vem o dinheiro, eu pensei que ele fosse explicar para vo 4 pensei que ele fosse explicar para você de vem o dinheiro do dossiê. Porque, olha, 45 dias eles não 4 pensei que ele fosse explicar para você de vem o dinheiro do dossiê. Porque, olha, 45 dias eles não

CORRUPÇÃO É ROUPA SUJA

6 ra nós trabalharmos juntos, combater a lavagem de dinheiro, porque COAF, Receita, tudo isso é do Gov

DINHEIRO PÚBLICO É LIXO

7 ício, desvio de dinheiro, vampiros, sanguessugas, dinheiro do povo jogado fora. E como se tratam as

DINHEIRO É UM OBJETO

8 e, foi a compra, o aluguel de deputados a peso de dinheiro, através do valerioduto. Nós vimos o escâ

DINHEIRO É UM ORGANISMO

9 amos com a questão do dossiê: 1 milhão $750 \mathrm{mil}$ em dinheiro vivo. Foram presos os dirigentes do PT, o

Concordância 12 - Usos de ‘dinheiro’ associados a corrupção, por Alckmin

Em suma, buscamos revelar semelhanças e diferenças entre os candidatos nos principais debates da campanha à presidência de 2006. A análise sugeriu mais semelhanças do que diferenças entre os candidatos, o que talvez tenha sido suscitado pelas regras dos encontros, que limitaram consideravelmente a expressão individual dos candidatos; eles tenderam a repetir fórmulas ensaiadas e condensadas que coubessem no tempo exíguo disponível para as respostas. Assim, uma crítica possível aos debates é que eles uniformizam os candidatos, na ânsia de garantir um tratamento justo aos participantes. Ao mesmo tempo, é sob essas condições pouco favoráveis que fica mais evidente a experiência de um orador público. Em nossa análise, fica nítida a vantagem de Lula sobre Alckmin, o que é corroborado pelas pesquisas de opinião, que foram favoráveis a Lula após os debates.

A metáfora é um elemento chave no discurso político (CHARTERISBLACK, 2005) e, por conseguinte, nos debates. A metáfora despontou na imprensa como assunto público por meio das referências ao estilo de oratória do presidente Lula, que utiliza comparações ditas populares para lidar com os assuntos de interesse nacional. Acreditamos que essa exposição pública do tema 'metáfora' tenha um lado positivo e um negativo. Ela é benéfica à medida que atrai atenção para esse tema fora dos círculos escolares, onde é normalmente tratada com recurso literário. Sob o aspecto desfavorável, ela nos leva a supor que as metáforas no discurso resumemse àquelas mais óbvias, que saltam aos olhos. Conforme mostramos, o estudo 
das metáforas em uso requer rigor teórico e todo um aparato metodológico na coleta e análise de dados que poucos na imprensa estão aptos a dispensar.

Nosso estudo possui várias limitações, entre elas a ausência de dois debates televisados (redes Band e Record) e a análise seletiva do vocabulário apontado pelo programa analisador de metáforas. Essas duas opções não nos permitiram identificar todas as metáforas dos debates. Apesar disso, as metáforas levantadas mostraram aspectos relevantes do discurso dos dois candidatos.

Este estudo reforçou o entendimento de que a Lingüística de Corpus é capaz de fornecer as ferramentas e o arcabouço metodológico para, com a Teoria da Metáfora Conceptual, lidar com o discurso efetivamente praticado pelos líderes políticos (CHARTERIS-BLACK, 2004). Cremos que essa junção é benéfica para os estudos da metáfora em geral.

\section{Referências Bibliográficas}

ABRAMOWITZ, A. I. The Impact of a Presidential Debate on Voter Rationality. American Journal of Political Science, Dallas, v.22, n.3, p.680-690. 1978.

BENOIT, W. L.; HANSEN, G. J. et al. A meta-analysis of the effects of viewing US presidential debates. Communication Monographs, Londres, v.70, n.4, p.335-350, 2003.

BERBER SARDINHA, T. Lingüística de Corpus. São Paulo: Manole, 2004. 410 p. Lula e a metáfora da conquista. São Paulo: PUC-SP, 2006. 27 f. Manuscrito.

. As metáforas do presidente Lula na perspectiva da Lingüística de Corpus: o caso do desenvolvimento. Trabalhos em Lingüistica Aplicada. Campinas. Em apreciação.

- A program for identifying metaphor candidates in corpora. International Journal of Corpus Linguistics. Amsterdam/Philadelphia. no prelo.

BIBER, D.; CONRAD, S. Lexical bundles in conversation and academic prose. In: HASSELGARD, H.; OKSEFJELL, S. (Org.). Out of Corpora -Studies in Honour of StigJohansson. Amsterdam/Atlanta, GA: Rodopi, 1999. p.181-190.

CAMERON, L. Metaphor in Educational Discourse. London: Continuum, 2003. x, 294 p.

CHARTERIS-BLACK, J. Corpus Approaches to Critical Metaphor Analysis. Basingstoke: Palgrave Macmillan, 2004. xv, 263 p.

Politicians and Rhetoric: the Persuasive Power of Metaphor.

Basingstoke: Palgrave Macmillan, 2005. xii, 239 p. 
CIENKI, A. Bush's and Gore's language and gestures in the 2000 U. S. presidential debates. Journal of Language and Politics, Amsterdam/ Philadelphia, v.3, n.3, p.409-440, 2004.

Metaphor in the "Strict Father" and "Nurturant Parent"cognitive models: Theoretical issues raised in an empirical study. Cognitive Linguistics, Berlin/Nova York, v.16, n.2, p.279-312, 2005.

DEIGNAN, A. Metaphor and Corpus Linguistics. Amsterdam/Philadelphia: John Benjamins, 2005. viii, 235 p.

GIBBS, R. W. The Poetics of Mind: Figurative Thought, Language, and Understanding. Cambridge: Cambridge University Press, 1994. ix, 527 p.

HELLWEG, S. A.; PFAU, M. et al. Televised Presidential Debates: Advocacy in Contemporary America: Praeger, 1992. xxiii, 168 p.

HOLBROOK, T. M. Political Learning from Presidential Debates. Political Behavior, Nova York, v.21, n.1, p.67-89, 1999.

HUNSTON, S. Corpora in Applied Linguistics. Cambridge: Cambridge University Press, 2002. 241 p.

KRAUS, S. Televised Presidential Debates and Public Policy. Mahwah, N.J.: Lawrence Erlbaum, 2000. xxi, 323 p.

LAKOFF, G. Moral Politics: How Liberals and Conservatives Think. Chicago: University of Chicago Press, 2002. xv, 471 p.

LAKOFF, G.; JOHNSON, M. Metaphors We Live By. Chicago: University of Chicago Press, 1980. xiii, 242 p.

PIZA, D. O debate como teatro. 2006. Disponível em: <http://blog. estadao.com.br/blog/piza/?title=mais_um_rebate\&more $=1 \& \mathrm{c}=1 \& \mathrm{tb}=1 \& \mathrm{pb}=1 .>$ Acesso em: 26 out. 2006.

PT. Lula Presidente: Plano de Governo 2007/2010. Brasilia, DF: Partido dos Trabalhadores, 2006. $34 \mathrm{p}$.

SCHROEDER, A. Presidential Debates: Forty Years of High-Risk TV. New York: Columbia University Press, 2000. x, 271 p.

SINCLAIR, J. M. Beginning the study of lexis. In: BAZELL, C. E. (Org.). In Memory of J. R. Firth. London: Longman, 1966. p.410-430.

VEJA.COM. Alckmin: corrupção espanta o crescimento. Veja Online, São Paulo, 29 ago. 2006. Disponível em: <http://vejaonline.abril.com.br>. Acesso em: 29 ago. 2006.

WRAY, A. Formulaic Language and the Lexicon. Cambridge: Cambridge University Press, 2002. 